Rong Fu, Li Li, ZhongHua Yu, Eve Afonso and Patrick Giraudoux*

\title{
Spatial and temporal distribution of Yunnan snub-nosed monkey, Rhinopithecus bieti, indices
}

https://doi.org/10.1515/mammalia-2017-0168

Received December 18, 2017; accepted March 29, 2018; previously published online May 18, 2018

\begin{abstract}
Studying elusive species of conservation concern might be difficult for technical and ethical reasons. However, censuses can be based on the observation of activity indices. When coupled to non-invasive genetic methods this approach can provide extremely precise information about population size, individual movements and diseases. However, the design of optimal sampling is dependent on a knowledge on group distribution and possible variations of detectability of index targets. The aim of this study was to document the distribution of Yunnan snub-nosed monkey indices in space and time in that perspective. Based on transects carried out across the range of a fed population and on counts along the trail across the range of a wild group, we show that 2-3 day stays of a group in a place of some hectares were sufficient to get an homogeneous distribution of indices. Furthermore, the number of indices found were dependent on both pig presence and season. On the other hand, on a large scale of 100 $\mathrm{km}^{2}$ indices were spatially distributed as nested clusters. Indices distribution indicated a strong preference towards southern slopes and altitudes ranging between 2900 and $3400 \mathrm{~m}$. Those observations pinpoint the importance of considering spatial scale to organise sampling designed to estimate population distribution.
\end{abstract}

Keywords: black and white snub nosed monkey; faeces; index transect.

\footnotetext{
*Corresponding author: Patrick Giraudoux, Laboratory of Wildlife Management and Ecosystem Health, Yunnan University of Finance and Economics, Kunming, China; Chrono-Environment Lab, University of Bourgogne Franche-Comté/CNRS USC INRA, Besançon, France; and Institut Universitaire de France, Paris, France, e-mail: patrick.giraudoux@univ-fcomte.fr

Rong Fu and Li Li: Laboratory of Wildlife Management and Ecosystem Health, Yunnan University of Finance and Economics, Kunming, China

ZhongHua Yu: National Nature Reserve of BaiMa XueShan, Tacheng, China

Eve Afonso: Chrono-Environment Lab, University of Bourgogne Franche-Comté/CNRS USC INRA, Besançon, France
}

Introduction

The Yunnan snub-nosed monkey, Rhinopithecus bieti, Milne-Edwards 1897, lives in one of the most extreme environments of any non-human primate. It is found in 15 discrete populations totalling less than 3000 animals, in northwestern Yunnan and southeastern Tibet, between the Jinsha (upper Yangtze) and the Lancang (upper Mekong) rivers, where it inhabits temperate alpine forest ecosystems and occasionally venture into very high elevations reaching $4700 \mathrm{~m}$ above sea level (Long et al. 1994, Li et al. 2015, Yu et al. 2016). The species is thought to be one of the most endangered in China, due to involuntary trapping by deer hunters, poaching, habitat loss especially from logging and habitat fragmentation particularly from agriculture encroachment and road network extension (Xiao et al. 2003, Liu et al. 2009, Quan et al. 2011). Rhinopithecus bieti is an elusive species in most of its range and for ethical reasons cannot be captured. So far, censuses are based on visual observation (Kirkpatrick et al. 1998), hearing and on detecting activity indices such as faeces (Zhao et al. 1988). To study species distribution and populationrelative densities using indices is not a new idea, and this has been undertaken many times on other species. For instance, Sadlier et al. (2004) and Webbon et al. (2004) have shown for foxes, Vulpes vulpes, Linnaeus 1758, that on a large spatial scale (e.g. national) and a coarse spatial resolution (1 km grid) scat counts are well correlated to other methods of population distribution estimation. By contrast on a smaller spatial scale (some hundreds of square kilometres) although fox scats are more easily found along trails, transects appear to be more precise (Giraudoux 1991, Guthlin et al. 2012). This underlines the fact that the way indices can be used are scale dependent. Furthermore, survey efforts should consider comparisons between habitats and seasons carefully in sampling design. For instance, detectability may vary according to many factors such as weather, vegetation height, etc. Although often crucial where study concerns elusive species, using indices must be implemented with a sufficient knowledge about any source of detectability variations beside population densities. Using multiple independent techniques (e.g. scat 
counts, snow tracking, counts on dens, camera trapping, etc.) to verify their relative value is recommended (Beltran et al. 1991, Gompper et al. 2006). In some cases, observations of indices along transects have provided efficient ways for monitoring seasonal and inter-annual fine changes in population densities on multiple scales from local up to regional as shown for grassland voles (Delattre et al. 1992, 1999, Giraudoux et al. 1997, Berthier et al. 2014).

The recent development of molecular ecology is currently renewing the study of wildlife populations and biodiversity monitoring (Waits and Paetkau 2005, Vigilant and Guschanski 2009, Bohmann et al. 2014). Genomic DNA can be obtained from a variety of sources that do not necessarily depend on handling or observing animals, like faeces, urine, hair, or shed skin. These non-invasive samples are particularly useful to study rare or elusive species, and can be used to count and identify individuals through genotyping, to determine gender and to identify species or diet items (Waits and Paetkau 2005). Genetic data are also used to assess habitat use, range size, mating systems, hybridisation, gene flow, dispersal barriers, pathogens and population size. Conservation biology benefits of genetic data to define management units and to provide insights into demographic patterns. Among the non-invasive samples, faeces may represent the most readily-available and easily-collected source of information (Kohn and Wayne 1997). Collecting faeces has the advantage of reducing the logistics of fieldwork and offers an opportunity to have hundreds of samples that can be managed later in the laboratory. In the case of $R h i-$ nopithecus bieti, molecular tools have been used on faeces to assess the population genetic structure and to define management units (Liu et al. 2007, 2009), and offer a promising approach to explore the ecology of this species.

The relevance of the results of such studies are largely dependent on a sampling design that incorporates a knowledge about population space-time distribution. For instance, extrapolation on large areas, or on other inappropriate time-space scales, of results obtained from a population distribution thought to be homogeneous from habitat analysis (e.g. remote sensing, etc.) but actually clustered, can lead to strongly biased estimations. It is thus important to gather field information which permits organising further sampling designs and to know the parameters that can explain variations in index abundance in space and time beside monkey population densities. The aim of this study is to describe the distribution patterns of Yunnan snub-nosed monkey indices in space and time in order to document further research on space occupation and molecular genetics.

\section{Materials and methods}

The study area concerns group \#9 of Liu et al. (2009). The group $(\mathrm{n}>400)$ ranges on an area of about $56 \mathrm{~km}^{2}(2500-$ $4000 \mathrm{~m}$ a.s.l) in the subtropical-temperate montane Samage Forest (part of Baimaxueshan National Nature Reserve) in the vicinity of Xiangguqing (响古箐) and Gehuaqing (格花箐) hamlets (Grueter et al. 2008, Li et al. 2008), at the north-west of Tacheng, between the upper reaches of the Lancang (upper Mekong) and Jinsha (upper Yangtse) rivers. Since 2008, in order to increase public awareness about monkey conservation and promote ecotourism locally, the guards on the reserve provide a small group of about 60 individuals with food (Bryoria sp. and Usnea sp. lichens, the natural staple food of this species, collected in the neighbourhood) in fixed stations of some hectares in the Xiangguqing valley every morning (Figure 1). The guards change the feeding station every 2-3 days to another site at some $100 \mathrm{~m}$ away in order to stimulate natural displacements that any Yunnan snub-nosed monkey group usually carry out to find food. During the feeding sessions, tourists easily see this group, here after named the "fed group". Although guards permanently monitor it, individuals move freely in the area and can mix with the rest of the population, here after named the "wild group". The wild group is very elusive with a range estimated at $52 \mathrm{~km}^{2}$ (Grueter et al. 2008). Long trekking in sloping mountains is necessary to observe individuals and presence indices and the details of the organisation and structure of this group of several hundred individuals is still poorly known (Grueter et al. 2008, Li et al. 2008, 2013).

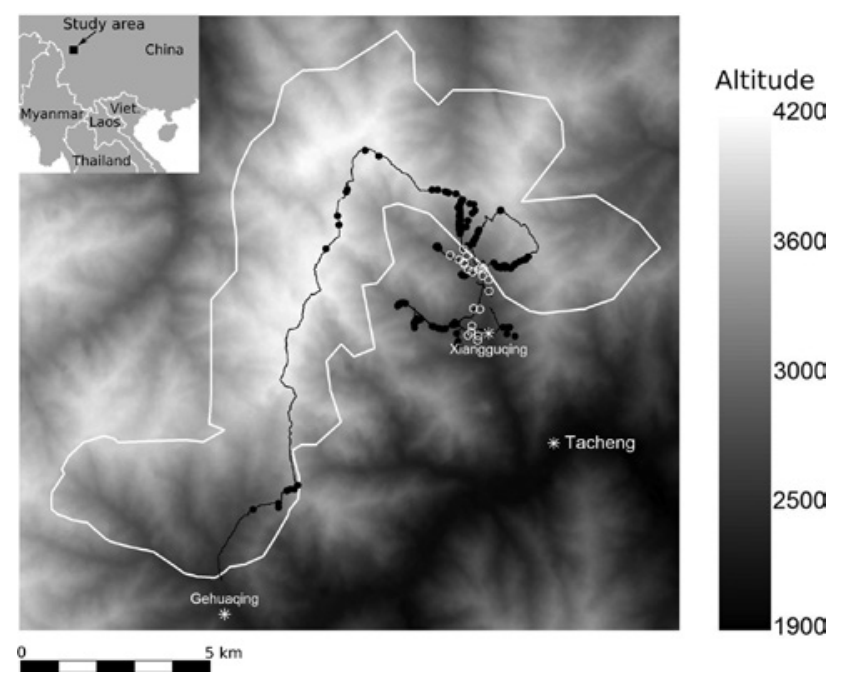

Figure 1: Map of the study area.

White line, border of the monkey distribution after Wong et al. (2013). Black lines, trails walked; black circles, location of indices of the wild group; white circles, location of the feeding stations; Viet., Vietnam. 


\section{Presence indices}

Presence indices were defined according to three categories following He et al. (2017) and interviews with the guards. (1) Feedings: faeces, food remains (lichens, leaves), gnawing prints, e.g. on twigs, (2) movements: broken bark, broken twigs, hairs, snow prints, etc. and (3) direct observation and hearing. Faeces are very characteristic and cannot be mistaken with other monkey species (e.g. Macaca mulata) in the area (Figure 2).

\section{Wild group}

We accompanied the guards during their regular surveys in the mountains. We georeferenced the track from the trail point where guards estimated that monkey presence was possible, to the end of the trail. Presence indices were georeferenced and slope and vegetation features were additionally recorded.

\section{Fed group}

The group was not disturbed during the feeding days, and we visited the area after guards flushed the group away to another feeding station. A transect crossing the area was walked and the track was georeferenced. Every presence
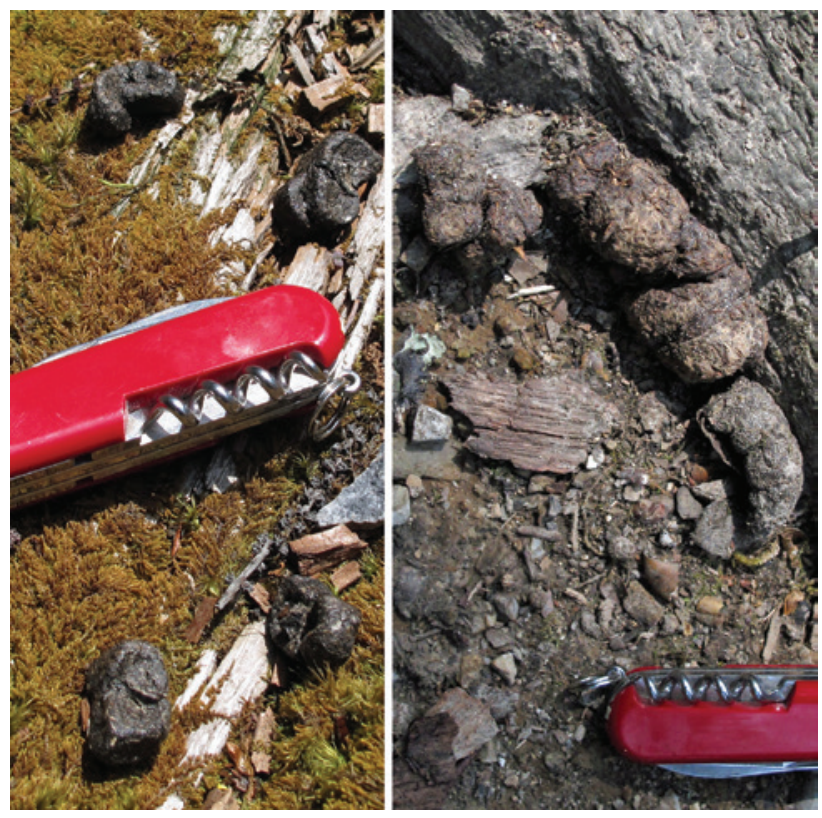

Figure 2: Faeces of Rhinopithecus bieti are generally smaller, dark, short and cylindric, and more or less scattered, compared to those of Macaca mulatta.

(Left) Yunnan snub nosed monkey (R. bieti) faeces. (Right) Rhesus monkey (M. mulatta) faeces, in the same area. index was georeferenced (except lichens, as these were provided by the guards). Additionally, we recorded the group residence duration, the presence of pigs, slope and vegetation features.

\section{Remote sensing}

Altitude, slope and aspect were derived using an ASTER Global Digital Elevation Model V002 at 30 m resolution and 10-20 m altitude precision (https://asterweb.jpl.nasa. gov/gdem.asp) (Caltech, Pasadena, CA, USA).

\section{Computings}

Computings were done using R 3.4.1 (R Core Team 2016) with the packages rgdal, sp (Bivand et al. 2013) and pgirmess (Giraudoux 2017) and Quantum GIS 2.18 (QGIS Development Team 2016).

We used SaTScan 9.4.2 to test the randomness of indices distribution according to spatial scan statistics developed by Kulldorff and Nagarwalla (1995). Here, we tested the null hypothesis that the presence or absence of indices in 100-m intervals along the track follows a binomial distribution. In brief, Kulldorff's method imposes a circular window on a map and moves the circle centre over each point location, so that the window includes different sets of neighbouring points at different positions. At each point location, the radius of the circle is increased continuously from 0 to a maximum containing at most $50 \%$ of the total number of points. The Kulldorff's method detects the potential clusters by calculating a likelihood ratio for each circle comparing the expected (under the null hypothesis) and observed frequency in and outside the circle. The circle with the maximum likelihood ratio among all radius circles at all possible point locations is considered the most likely cluster (called the primary cluster). It also identifies secondary clusters that have a significantly larger likelihood ratio but are not the primary cluster, etc. Here both the frequency of indices higher than average (high rate cluster), and lower than average (low rate clusters) were taken into account.

Index density differences according to environmental variables and sampling pressure were modelled using a generalised linear model with a Poisson link function, and the significance of coefficients was tested using analysis of variance (Venables and Ripley 2003).

Metadata on trail and index locations can be accessed via the dat@osu portal (https://dataosu.obs-besancon.fr/ FR-18008901306731-2018-03-20) (University of FrancheComté, Besançon, France). 


\section{Results}

\section{Wild group}

Fourteen trails were walked from the 20th of March to the 9th of June 2017 (among them four tracks could not be exactly recorded by global positioning system [GPS]), totalling more than $82 \mathrm{~km}$ between 2500 and $4130 \mathrm{~m}$ of altitude (Figure 1). Here we found a number of indices out of the known distribution range of the group, which indicated that it has shifted or enlarged.

Figure 3 shows that the frequency of indices peaked between 2900 and $3400 \mathrm{~m}$ of altitude. A comparison with altitude frequencies walked along the trails rules out a random distribution (chi-squared $\left(\chi^{2}\right)$-test, $\mathrm{p}<0.0001$ ) and indicates a clear group preference for this altitude range. Furthermore, we found a much larger number of indices on south slopes than what would be expected from a random distribution (comparison with the slope frequencies walked along the trails: $\chi^{2}$-test, $\left.\mathrm{p}<0.0001\right)$ (Figure 4).

Indices were not randomly distributed along the tracks and clusters were identified. The larger high rate clusters was found in the Xiangguqing valley $(\mathrm{p}<0.001)$, including two smaller secondary higher rate clusters $(p<0.001$ in both cases), and a low rate cluster was identified on the southern part of the DaXunHu track crossing the heights between Xiangguqing and Gehuaqing $(\mathrm{p}=0.001)$ (Figure 5).

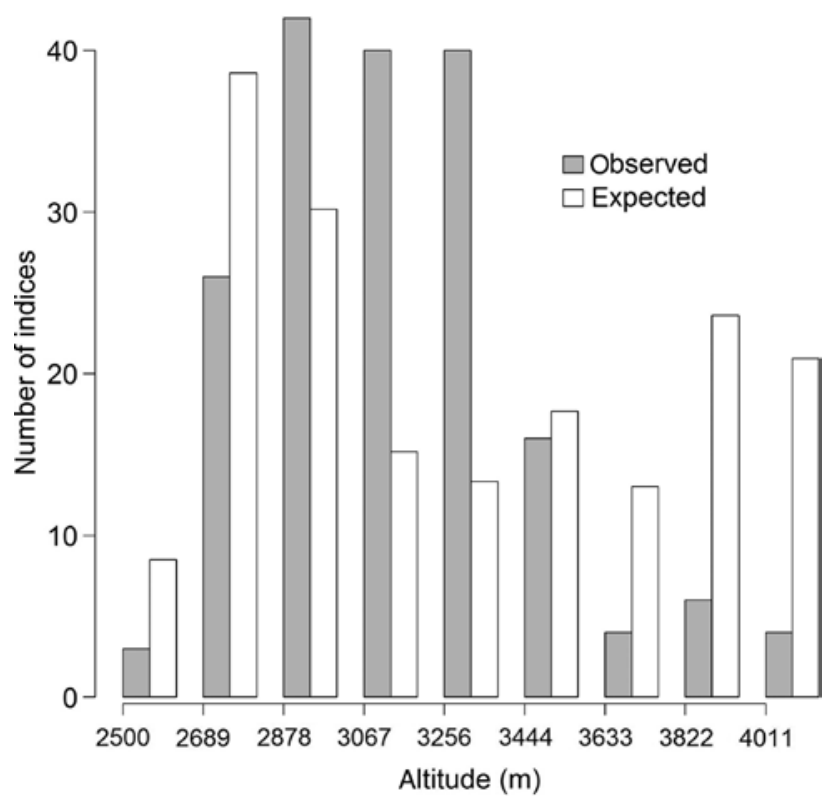

Figure 3: Altitude distribution.

The expected distribution corresponds to the number of indices that would have been observed if they were randomly distributed along the trail.

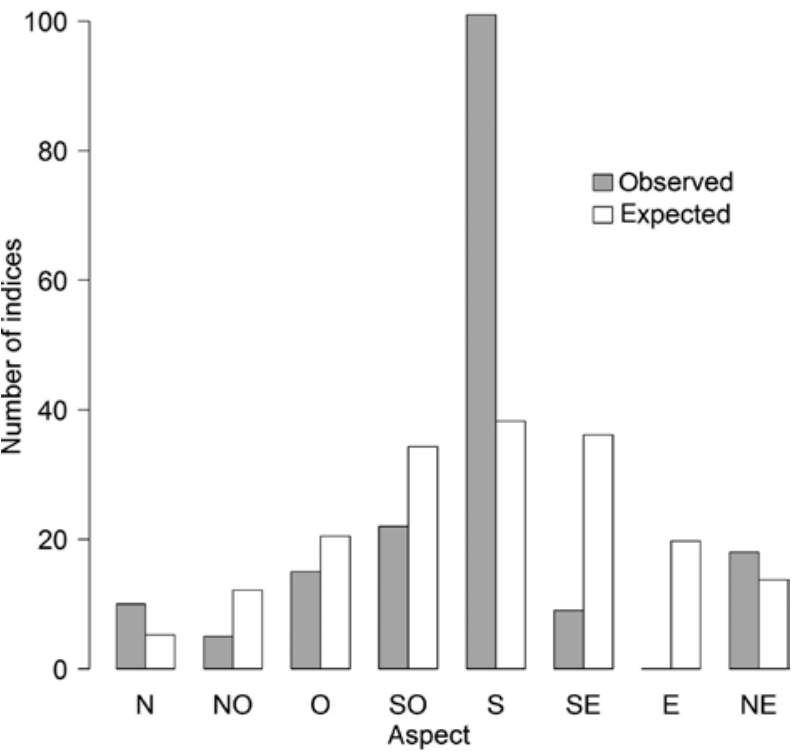

Figure 4: Aspect distribution.

The expected distribution corresponds to the number of indices that would have been observed if they were randomly distributed along the trail.

Table 1 shows that once trekking in monkey habitats, $850 \mathrm{~m}$ in average (minimum $200 \mathrm{~m}$, maximum $2000 \mathrm{~m}$ ) were walked before finding the first indices.

\section{Fed group}

Twenty-two transects were walked across feeding stations from the 15th of March to the 19th of June 2017, totalling $6.8 \mathrm{~km}$. After a monkey stay of 2-3 days, indices could be found in virtually every $100 \mathrm{~m}$ transect interval and no cluster could be detected (Figure 6).

Controlling for the monkey residence time at the feeding station and transect length, the number of monkey

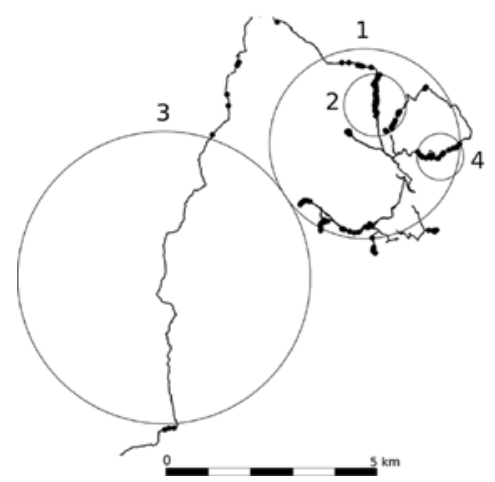

Figure 5: Cluster distribution: 1, 2, 4 are high rates clusters, 3 is a low-rate cluster.

Black dots are index positions. 
Table 1: Details of the trail characteristics and number of indices of the wild group.

\begin{tabular}{lrrrrrr}
\hline ID track & $\begin{array}{r}\text { Length } \\
(\mathrm{m})\end{array}$ & $\begin{array}{r}\text { Distance } \\
\text { to the first } \\
\text { index }(\mathrm{m})\end{array}$ & Faeces & $\begin{array}{r}\text { Broken } \\
\text { twig }\end{array}$ & $\begin{array}{r}\text { Lichen } \\
\text { or leaf } \\
\text { eaten }\end{array}$ & $\begin{array}{r}\text { Visual } \\
\text { contact or } \\
\text { hearing }\end{array}$ \\
\hline 1 & 7168 & 267 & & & & 1 \\
2 & 7537 & 214 & 4 & & & 1 \\
3 & 1130 & 925 & 1 & & 7 & 2 \\
4 & 2794 & 646 & 3 & 2 & 2 & \\
5 & 7068 & 737 & 13 & 10 & 5 & \\
$7+8$ & 8712 & 1927 & 11 & 23 & & \\
9 & 8124 & 693 & 22 & 16 & & \\
12 & 3029 & 1155 & 6 & 7 & 1 & \\
$13+14$ & 22,554 & 1136 & 14 & 29 & & \\
\hline
\end{tabular}

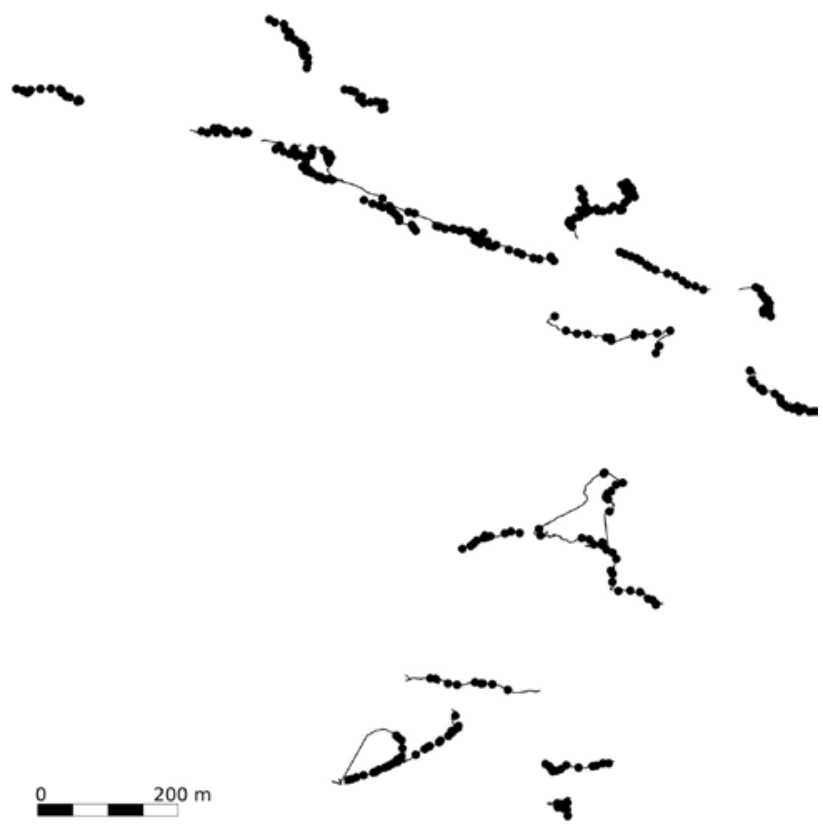

Figure 6: Distribution of indices (black circles) along the transects walked at the feeding stations.

faeces was 4.2 times larger where pigs were absent ( 0.6 vs. 2.7 faeces $\cdot$ day $^{-1} \cdot \mathrm{km}^{-1}$ ). On the contrary, the number of other indices were 1.43 times larger where pigs were present $\left(20.4,29.2\right.$ faeces $\cdot$ day $\left.^{-1} \cdot \mathrm{km}^{-1}\right)$ (Table 2).

Figure 7 indicates that index densities increased during the study period.

\section{Discussion}

If a relatively large number of studies have looked for a correlation between mammal presence indices, spatial
Table 2: Coefficients of the generalised linear models (Poisson link).

\begin{tabular}{lrrrr}
\hline Term & Estimate & Standard error & Risk ratio & p-Value \\
\hline Number of faeces & & & & \\
$\quad$ Intercept) & 1.1200 & 0.6846 & - & - \\
Length & -0.0004 & 0.0007 & - & 0.5468 \\
$\quad$ Residence time & 0.2501 & 0.3609 & - & 0.4884 \\
$\quad$ Pig presence & -1.4337 & 0.3773 & 0.24 & 0.0001 \\
Other indices & & & & \\
$\quad$ Intercept) & 2.1973 & 0.2726 & - & - \\
Length & 0.0008 & 0.0002 & - & 0.0003 \\
Residence time & -0.0337 & 0.1429 & - & 0.8136 \\
Pig presence & 0.3611 & 0.1791 & 1.43 & 0.0438 \\
\hline
\end{tabular}

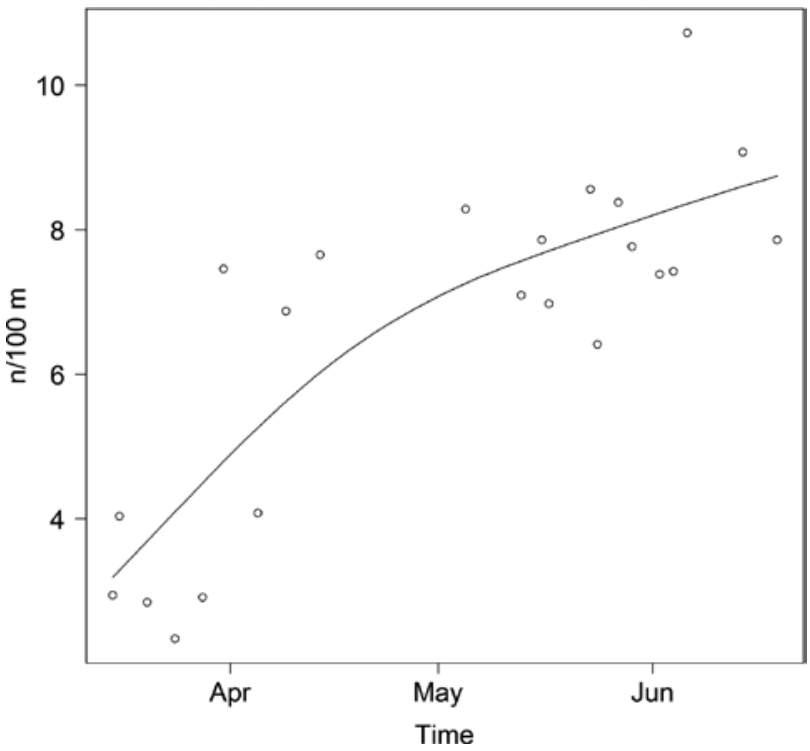

Figure 7: Variations in index density during the study period.

distribution and population densities, to our knowledge only one concerns a non-human primate. Zhao et al. (1988) were the first authors to determine ranging patterns of Rhinopithecus bieti in a census realised in the first fortnight of April 1986, at approximately $96 \mathrm{~km}$ north of our study area, at the south-western distribution range of group \#5 (Li et al. 2015), one of the most northern groups of $R$. bieti in Yunnan. There Zhao et al. (1988) found that monkeys tended to use the upper part of the forest ranging between 3900 and $4100 \mathrm{~m}$ of altitude. Quan et al. (2011) studying another group, about $100 \mathrm{~km}$ further north-west, in the Tibet Autonomous Region, later found that this preference for higher altitude in winter was a preference for areas with higher solar radiation and longer sunshine duration. However, in those studies little information is available about the possible variations of detectability and no information about general distribution patterns over large areas. 
The present study aims at documenting the distribution patterns of indices locally in places where a known number of monkeys ( $\mathrm{n} \sim 60)$ was observed staying for 2-3 days at the same place and on a larger area of approximately $100 \mathrm{~km}^{2}$ where a large but imprecise number $(>400$ individuals) was known to roam permanently. Here we show that 2-3 days were enough to spread homogeneously with conspicuous indices virtually every 100-m interval of transects carried out in a feeding area. However, the total number of indices found was dependent on pig presence. A lower number of faeces was observed where pigs were present, which was obviously due to the fact that pigs were actively searching and eating monkey faeces (guards and Fu Rong's personal observations). Moreover, the index detectability increased from March to June. This might be due to late snowfalls in March, the recent snowfall covering the ground and decreasing index detectability at that period.

Our study shows that on a larger scale (some tens of square kilometres), contrary to what has been observed in Zhao et al. (1988) and Quan et al. (2011) the Qiangguqing population did not prefer higher altitude, with a larger number of indices found between 2900 and $3400 \mathrm{~m}$. However, this population showed an extremely strong preference for southern slopes, possibly as a way to fulfil their sunshine needs in the Qiangguqing valleys.

Monkey indices distributed in nested clusters, with clusters of high or very high-index densities and a large area where no indices could be found. This observation pinpoints the importance of careful attention to the scale of the study and the challenges of integrating overdispersed (nested) distribution patterns to describe spatial distributions (Hobbs 2003). In our case, it is obvious that more work is needed on population behaviour to establish a correspondence between indices and the monkey population structures in space and time. As direct and detailed observation of a large number of wild animals can be extremely difficult, using faeces and genetic markers (e.g. permitting individual identification) is an extremely promising way to elucidate how snub-nosed monkeys range over large areas. The patchy distribution observed also indicates that sampling indices need to be designed on large scales of several tens of square kilometres to assess population distribution properly.

Acknowledgments: We thank Zhong Tai, Yu XinMing and all the guards of the National Nature Reserve of BaiMa XueShan for their invaluable help and advice. This work has been carried out with the support of GDRI EHEDE (http://gdri-ehede.univ-fcomte.fr).

\section{References}

Beltran, J.F., M. Delibes and J.R. Rau. 1991. Methods of censusing red fox (Vulpes vulpes) populations. Hystrix 3: 199-214.

Berthier, K., S. Piry, J.F. Cosson, P. Giraudoux, J.C. Foltete, R. Defaut, D. Truchetet and X. Lambin. 2014. Dispersal, landscape and travelling waves in cyclic vole populations. Ecol. Lett. 17: 53-64.

Bivand, R.S., E.J. Pebesma and V. Gomez-Rubio. 2013. Applied spatial data analysis with R. Second edition. Springer, New York. pp. 405.

Bohmann, K., A. Evans, M.T.P. Gilbert, G.R. Carvalho, S. Creer, M. Knapp, D.W. Yu and M. de Bruyn. 2014. Environmental DNA for wildlife biology and biodiversity monitoring. Trends Ecol. Evol. 29: 358-367.

Delattre, P., P. Giraudoux, J. Baudry, D. Truchetet, P. Musard, M. Toussaint, P. Stahl, M.L. Poule, M. Artois, J.P. Damange and J.P. Quere. 1992. Land use patterns and types of common vole (Microtus arvalis) population kinetics. Agric. Ecosyst. Environ. 39: 153-169.

Delattre, P., B. De Sousa, E. Fichet, J.P. Quéré and P. Giraudoux. 1999. Vole outbreaks in a landscape context: evidence from a six year study of Microtus arvalis. Landsc. Ecol. 14: 401-412.

Giraudoux, P. 1991. Utilisation de l'espace par les hôtes du ténia multiloculaire (Echinococcus multilocularis): conséquences épidémiologiques. Université de Bourgogne, Dijon, France. pp. 90.

Giraudoux, P. 2017. pgirmess: Data analysis in ecology. R package version 1.6.8. http://perso.orange.fr/giraudoux.

Giraudoux, P., P. Delattre, M. Habert, J.P. Quere, S. Deblay, R. Defaut, R. Duhamel, M.F. Moissenet, D. Salvi and D. Truchetet. 1997. Population dynamics of fossorial water vole (Arvicola terrestris scherman): a land usage and landscape perpective. Agric. Ecosyst. Environ. 66: 47-60.

Gompper, M.E., R.W. Kays, J.C. Ray, S.D. Lapoint, D.A. Bogan and J.R. Cryan. 2006. A comparison of noninvasive techniques to survey carnivore communities in northeastern North America. Wildl. Soc. Bull. 34: 1142-1151.

Grueter, C.C., D.Y. Li, C.P. van Schaik, B.P. Ren, Y.C. Long and F.W. Wei. 2008. Ranging of Rhinopithecus bieti in the Samage Forest, China. I. Characteristics of Range Use. Int. J. Primatol. 29: 1121-1145.

Guthlin, D., M. Kroschel, H. Kuchenhoff and I. Storch. 2012. Faecal sampling along trails: a questionable standard for estimating red fox Vulpes vulpes abundance. Wildlife Biol. 18: 374-382.

Hobbs, N.T. 2003. Challenges and opportunities in integrating ecological knowledge across scales. Forest Ecol. Manag. 181: 223-238.

Kirkpatrick, R.C., Y.C. Long, T. Zhong and L. Xiao. 1998. Social organization and range use in the Yunnan snub-nosed monkey Rhinopithecus bieti. Int. J. Primatol. 19: 13-51.

Kohn, M.H. and R.K. Wayne. 1997. Facts from feces revisited. Trends Ecol. Evol. 12: 223-227.

Kulldorff, M. and N. Nagarwalla. 1995. Spatial disease clusters: detection and inference. Stat. Med. 14: 799-810.

Li, D.Y., C.C. Grueter, B.P. Ren, Y.C. Long, M. Li, Z.S. Peng and F.W. Wei. 2008. Ranging of Rhinopithecus bieti in the Samage Forest, China. II. Use of land cover types and altitudes. Int. J. Primatol. 29: 1147-1173.

Li, D.Y., C.C. Grueter, B.P. Ren, M. Li, Z.S. Peng and F.W. Wei. 2013. Distribution of sleeping sites of the Yunnan snub-nosed monkey (Rhinopithecus bieti) in the Samage Forest, China. Integr. Zool. 8: 327-334. 
Li, L., Y. Xue, G. Wu, D. Li and P. Giraudoux. 2015. Potential habitat corridors and restoration areas for the black-and-white snubnosed monkey Rhinopithecus bieti in Yunnan, China. Oryx 49: 719-726.

Liu, Z., B. Ren, F. Wei, Y. Long, Y. Hao and M. Li. 2007. Phylogeography and population structure of the Yunnan snub-nosed monkey (Rhinopithecus bieti) inferred from mitochondrial control region DNA sequence analysis. Mol. Ecol. 16: 3334-3349.

Liu, Z.J., B.P. Ren, R.D. Wu, L. Zhao, Y.L. Hao, B.S. Wang, F.W. Wei, Y.C. Long and M. Li. 2009. The effect of landscape features on population genetic structure in Yunnan snub-nosed monkeys (Rhinopithecus bieti) implies an anthropogenic genetic discontinuity. Mol. Ecol. 18: 3831-3846.

Long, Y.C., C.R. Kirkpatrick, Zhongtai and Xiaolin. 1994. Report on the distribution, population, and ecology of the Yunnan snubnosed monkey (Rhinopithecus bieti). Primates 35: 241-250.

NASA JPL. 2009. ASTER Global Digital Elevation Model [Data set], ed. N. JPL.

QGIS Development Team. 2016. QGIS Geographic Information System. http://www.qgis.org/. Downloaded on 18/12/2016.

Quan, R.C., G.P. Ren, J.E. Behm, L. Wang, Y. Huang, Y.C. Long and J.G. Zhu. 2011. Why does Rhinopithecus bieti prefer the highest elevation range in winter? A test of the sunshine hypothesis. PLoS One 6: e24449.

R Core Team. 2016. R: A language and environment for statistical computing. https://www.R-project.org/. Downloaded on $17 / 12 / 2016$.

Reserve de Baimaxueshan. 2017. Observation in the sacred habitat of the Yunnan snub-nosed monkey (in Chinese). Yunnan's people, Kunming. pp. 179-188.

Sadlier, L.M.J., C.C. Webbon, P.J. Baker and S. Harris. 2004. Methods of monitoring red foxes Vulpes vulpes and badgers
Meles meles: are field signs the answer? Mamm. Rev. 34: 75-98.

Venables, W. and B. Ripley. 2003. Modern applied statistics with S. Springer, New York. pp. 495.

Vigilant, L. and K. Guschanski. 2009. Using genetics to understand the dynamics of wild primate populations. Primates 50: 105-120.

Waits, L.P. and D. Paetkau. 2005. Noninvasive genetic sampling tools for wildlife biologists: a review of applications and recommendations for accurate data collection. J. Wildl. Manag. 69: 1419-1433.

Webbon, C.C., P.J. Baker and S. Harris. 2004. Faecal density counts for monitoring changes in red fox numbers in rural Britain. J. Appl. Ecol. 41: 768-779.

Wong, M.H.G., R.Q. Li, M. Xu and Y.C. Long. 2013. An integrative approach to assessing the potential impacts of climate change on the Yunnan snub-nosed monkey. Biol. Conserv. 158: 401-409.

Xiao, W., W. Ding, L.W. Cui, R.L. Zhou and Q.K. Zhao. 2003. Habitat degradation of Rhinopithecus bieti in Yunnan, China. Int. J. Primatol. 24: 389-398.

Yu, L., G.-D. Wang, J. Ruan, Y.-B. Chen, C.-P. Yang, X. Cao, H. Wu, Y.-H. Liu, Z.-L. Du, X.-P. Wang, J. Yang, S.-C. Cheng, L. Zhong, L. Wang, X. Wang, J.-Y. Hu, L. Fang, B. Bai, K.-L. Wang, N. Yuan, S.-F. Wu, B.-G. Li, J.-G. Zhang, Y.-Q. Yang, C.-L. Zhang, Y.-C. Long, H.-S. Li, J.-Y. Yang, D.M. Irwin, O.A. Ryder, Y. Li, C.-I. Wu and Y.-P. Zhang. 2016. Genomic analysis of snub-nosed monkeys (Rhinopithecus) identifies genes and processes related to high-altitude adaptation. Nat. Genet. 48: 947-952.

Zhao, Q., S. He, B. Wu and L.T. Nash. 1988. Excrement distribution and habitat use in Rhinopithecus bieti in winter. Am. J. Primatol. 16: $275-284$. 